\title{
Regional Interaction and Effects of Universities: Introduction to the Special Issue
}

\author{
Thomas Brenner $^{1}$ (D) Daniel Schiller ${ }^{2}$
}

Accepted: 24 September 2019 / Published online: 17 October 2019

(C) Springer-Verlag GmbH Germany, part of Springer Nature 2019

\section{Introduction: Regional Interaction and Effects of Universities}

In recent years universities have changed with regard to their character, organization and tasks they are expected to fulfil (Blume et al. 2017), not only in continental Europe, but also around the world. Organization has become more centralized and more oriented towards efficiency and excellence. In the context of these changes, universities are nowadays expected to provide more than scientific publications and graduates. Their so-called 'third mission' is based on widespread interaction with the economy, policy makers, and the wider society. This also includes a stronger interaction within the region. As a consequence, an increasing contribution to innovation, economic growth, structural change, societal development, and the attraction of people is expected at the regional level.

These new aspects of universities' importance for regions implies various new research strands. While the relevance of universities for sustainable developments in regions has been addressed by a recent special issue of this journal (Koenig et al. 2017; Roesler and Brökel 2017; Radinger-Peer and Pflitsch 2017; Brenner and Pflitsch 2017), this special issue continues on the topic with contributions on two further aspects: Two of the four papers in this special issue aim at providing a more differentiated understanding of university effects and network formation. The focus of the two other papers in this special issue is on teaching-related forms of interaction and effects of universities on migration.

\section{T. Brenner}

thomas.brenner@uni-marburg.de

1 Department of Geography, Philipps University Marburg, Deutschhausstr. 10, 35032 Marburg, Germany

2 Institute of Geography and Geology, University of Greifswald, Greifswald, Germany 
There is a need for a more differentiated understanding of the nature and variety of innovation induced by universities with a specific focus on their degree of novelty (Edwards-Schachter 2018). The breakthrough of digitalization and the normative shift of innovation towards contributing to tackling the so-called 'Grand Societal Challenges' require disruptive changes in existing technological paths. Within innovation studies, this is reflected by a new interest in radical innovations (Chrstensen et al. 2015). From a conceptual perspective, it is expected that universities have the potential to serve as 'change agents' and are potentially well-equipped to bring forward disruptive changes (Radinger-Peer and Stoeglehner 2013). However, there is yet insufficient empirical evidence on whether collaboration with universities really has a positive impact on the degree of novelty of innovations. This issue is addressed by the first paper by Arant et al. (2019, in this issue).

The properties of networks formed by universities and individual academics have been studied widely in the literature (Perkmann et al. 2013) with a particular focus on their spatial dimension (e.g. Schiller and Revilla Diez 2010; Trippl 2013). However, the processes and motivations underlying the formation of networks of academics have not yet been fully understood. More recently, Kroll et al. (2016) provided evidence for Germany on academics' objectives for regional engagement. Based on a paper by Engel et al. (2017), the formation of networks is now also understood as an entrepreneurial activity by academics. These notions are starting point for more in-depth investigation into the characteristics of this activity. Understanding the processes of network formation on different spatial scales from an individual perspective - as it is done in the second paper by Ahoba-Sam and Charles (2019, in this issue) - is of high relevance, because it will inform policy makers about meaningful designs of measures to promote regional engagement of academics.

Teaching-related collaboration modes of universities have been underrepresented in the literature if compared to research-related and entrepreneurial modes, even though studies in different contexts have shown that they are at least of similar importance (e.g. Koschatzky (2014) for Germany or Schiller and Brimble (2009) for Thailand). In the context of the increasing lack of qualified labor, the impact of the university options on the decision to study is of specific interest-a topic addressed in the third paper by Wessling (2019, in this issue). A related issue is the question of whether universities are able to attract people who remain in the region afterwards and increase the availability of qualified labor. Many studies have already analyzed the migration behavior of graduates (e.g. Busch and Weigert 2010; Abreu et al. 2014; Buenstorf et al. 2016; von Proff et al. 2016). The fourth paper by Oggenfuss (2019, in this issue) adds an analysis of Switzerland to this research.

This special issue originated from sessions on Universities and their Contribution to Innovation, Growth and Development at the Regional Level that were organized by the editors at the Global Conference of Economic Geography 2018 in Cologne.

\section{The Articles in this Special Issue}

The contribution by William Arant, Dirk Fornahl, Nils Grashof, Kolja Hesse and Cathrin Söllner (2019, this issue) studies the role that university-industry collabo- 
rations play in radical innovations. To this end data on subsidies and patents for 8404 firms is used. Radical innovations are defined as innovations that are patented with a new combination of technology classifications. The collaboration activity of a firm is measured by the subsidies that it received together with partners. The study finds that radical innovations are more likely to be made by firms that have more collaborations of all kinds-with universities, research institutes and other companies. Collaborations with research institutes seem to matter most and these are also the only ones for which a higher number of cognitively distant collaborations increases the likelihood of radical innovations significantly. For collaborations with universities significant increases are only found for more geographically distant collaborations.

Rhoda Ahoba-Sam and David Charles employ the theories of causation and effectuation in their paper (2019, this issue) to explore how personal networks of academics are initiated. Causation is defined as a goal-directed approach that rests on the logic of prediction, while effectuation refers to emergent and unordered approaches focused on co-creation. While the importance of collaborations by scientists for both the dissemination of new knowledge and identifying opportunities through which knowledge could be converted into commercial form is well-described in the literature, their contribution aims at understanding how these networks actually come about. The empirical analysis is based on information about the networks of 12 academics at the University of Stavanger, Norway, which were collected by in-depth interviews. The results show that both causation and effectuation are employed by academics when building their networks. However, networks with industry partners were more often associated with causation, while academic networks were built on effectuation. For networks at the regional level, they found a mixture of both approaches. The results imply, that characteristics of the collaboration partner are more important for the choice between causation and effectuation than the spatial scale.

Whether school graduates go to university or not is studied in the paper by Katarina Wessling (2019, this issue). Micro-level data on 1654 individuals in Germany is used to study the individual and regional determinants for the decision to study. Regional factors are the economic situation, the university orientation and the study opportunities and they are studied for different ranges of the considered spatial surrounding. This allows for interesting findings on the relevance of these factors' distances. It is found that all regional factors are relevant within a distance up to 60 min travel time. This means that the economic situation (unemployment rate) and the present universities within a commuting distance matter significantly for the decision of school graduates to take up a university study. It is also found that nearby traditional universities increase the probability of studying in addition to the pure share of students in the region. In addition, the changes of the importance of the regional factors over time are analysed, showing that the relevance of unemployment and nearby traditional universities increases, while the relevance of the overall study opportunities decreases.

Chantal Oggenfuss (2019, in this issue) studies the mobility of students in Switzerland after their studies. Similar to other findings in the literature, three quarter of the students that left their home canton for studying move again after their 
study. Many of them move back to their home canton but one third moves on to a third canton. The paper studies the influence of personal, university and canton characteristics on the decision to stay, return or move on. The results provide important information about what kind of cantons are able to attract and keep students. A higher GDP makes it more likely that students stay in the canton to which they moved for studying, while higher taxes make it more likely that people that have left a region for studying do not come back. A very interesting finding is that students performing better in their study are less likely to return to their home canton. This implies that regions with less attractive conditions (such as high taxes and low GDP) do not only loose people but loose the better performing people.

\section{Concluding remarks}

It can be expected that the interaction between universities and the region will remain an important research topic in, at least, the near future. On the one hand, the tasks of universities have changed a lot in recent years, implying many open questions of relevance in science and practice. While many studies have already analyzed the interaction between universities and the local economy (see above), the recent changes in universities' behavior and tasks might well make some older findings outdated. Sufficiently new data is just becoming available and it will be interesting to see how the regional effects and interactions of universities have changed. Hopefully, upcoming research will also focus on these changes within the last 20 years.

On the other hand, migration and qualified labor are two main actual issues in our society. Universities play a role for both of them. They educate people and attract them to the region. Furthermore, life-long learning will play a stronger role in the future. While many studies have been conducted on the migration behavior of graduates in recent years, the question of whether universities are an adequate mean to solve the lack of qualified people especially in non-metropolitan areas is still unanswered. Studies on the effects of universities especially in more rural and/or economically lagging regions would be of strong interest in this context.

\section{References}

Abreu M, Faggian A, McCann P (2014) Migration and inter-industry mobility of UK graduates. J Econ Geogr 15:353-385

Ahoba-Sam R, Charles D (2019) Building of academics' networks - an analysis based on causation and effectuation theory. Rev Reg Res. https://doi.org/10.1007/s10037-019-00134-2 (this issue)

Arant W, Fornahl D, Grashof N, Hesse K, Söllner C (2019) University-industry collaborations-the key to radical innovations? Rev Reg Res. https://doi.org/10.1007/s10037-019-00133-3 (this issue)

Blume L, Brenner T, Buenstorf G (2017) Universities and sustainable regional development: introduction to the special issue. Rev Reg Res 37:103-109

Brenner T, Pflitsch G (2017) The raise of publications on sustainability - a case study in Germany. Rev Reg Res 37:189-225

Buenstorf G, Geissler M, Krabel S (2016) Locations of labour market entry by German university graduates: is (regional) beauty in the eye of the beholder? Rev Reg Res 36:29-49

Busch O, Weigert B (2010) Where have all the graduates gone? Internal cross-state migration of graduates in Germany 1984-2004. Ann Reg Sci 44:559-572 
Christensen CM, Raynor ME, McDonald R (2015) What is disruptive innovation. Harv Bus Rev 93:44-53

Edwards-Schachter M (2018) The nature and variety of innovation. Int J Innov Stud 2:65-79

Engel Y, Kaandorp M, Elfring T (2017) Toward a dynamic process model of entrepreneurial networking under uncertainty. J Bus Ventur 32:35-51

Koenig J, Brenner T, Buenstorf G (2017) Regional effects of university funding: excellence at the cost of regional disparity? Rev Reg Res 37:111-133

Koschatzky K (2014) New forms of regional interaction between universities and industry evidence from Germany. Arbeitspapiere Unternehmen und Region, vol R3/2014. Fraunhofer ISI, Karlsruhe

Kroll H, Dornbusch F, Schnabl E (2016) Universities' regional involvement in Germany: how academics' objectives and opportunity shape choices of activity. Reg Stud 50:1595-1610

Oggenfuss C (2019) Are they coming back? The mobility of university graduates in Switzerland. Rev Reg Res. https://doi.org/10.1007/s10037-019-00132-4 (this issue)

Perkmann M, Tartari V, McKelvey M, Autio E, Broström A, D’Este P, Fini R, Geuna A, Grimaldi R, Hughes A, Krabel S, Kitson M, Llerena P, Lissoni F, Salter A, Sobrero M (2013) Academic engagement and commercialisation: a review of the literature on university-industry relations. Res Policy 42:423-442

Radinger-Peer V, Pflitsch G (2017) The role of higher education institutions in regional transition paths towards sustainability. Rev Reg Res 37:161-187

Radinger-Peer V, Stoeglehner G (2013) Universities as change agents for sustainability-framing the role of knowledge transfer and generation in regional development processes. J Clean Prod 44:85-95

Roesler C, Broekel T (2017) The role of universities in a network of subsidized R\&D collaboration: the case of the biotechnology-industry in Germany. Rev Reg Res 37:135-160

Schiller D, Brimble P (2009) Capacity building for university-industry linkages in developing countries: the case of the Thai Higher Education Development Project. Sci Technol Soc 14:59-92

Schiller D, Revilla Diez J (2010) Local embeddedness of knowledge spillover agents: empirical evidence from German star scientists. Pap Reg Sci 89:275-294

Trippl M (2013) Scientific mobility and knowledge transfer at the interregional and Intraregional level. Reg Stud 47:1653-1667

Von Proff S, Duschl M, Brenner T (2016) Motives behind the mobility of university graduates—a study of three German universities. Rev Reg Res 37:39-58

Wessling K (2019) Where do regional influences matter? Effects of socio-spatial indicators on transitions from secondary school to university. Rev Reg Res. https://doi.org/10.1007/s10037-019-00131-5 (this issue)

Publisher's Note Springer Nature remains neutral with regard to jurisdictional claims in published maps and institutional affiliations. 